\title{
Infection Control Measures in Some Selected Private Dental Clinics of Dhaka City
}

\author{
I Ahmed $^{1}, \mathrm{~J} \mathrm{Barua}^{2}$, KS Imtiaz $^{3}$, SZ Eusufzai $^{4}$, MT Mustafa $^{5}$, MM Haque $^{6}$, NB Jamayet $^{7}$
}

\begin{abstract}
Infection is one of the most vital problems in health care service worldwide. A cross-sectional study was conducted to assess the standard and level of current infection control practice in the Dental clinics in Dhaka city. A total 110 purposively selected respondents participated in this study, most of them were from middle age group. Among them 68\% were male and $32 \%$ were female. $62 \%$ respondents had graduate level education. By length of practice duration 53.6\% had 5-10 years experience and 30.0\% treat average 5-10 patients daily. Among the total respondents 77\% of Dental surgeons were vaccinated against tetanus and hepatitis and 56\% of respondents used to wash hands by water with soap. Within the total participating dentists $66 \%$ gave the history of habitual wearing of disposable gloves, $70.0 \%$ used disposable masks and $26.4 \%$ wore disposable clothes. The study also reported that, $44 \%$ of respondents usually washed clinical contact surface in the dental operatory by disinfectants and $33 \%$ of respondents cleaned the operatory surfaces after patient's treatment by water and antiseptics. The study revealed that almost all dental surgeons used to use the disposable instruments \& accessories in the clinic, 41\% clinicians used dettol in the clinic as disinfecting solution and $35.8 \%$ respondents sterilized their instruments by autoclave. The research work found that $73.6 \%$ respondents mentioned to clean the prosthodontic instruments by detergent wash, $68.2 \%$ mentioned to use glass bid sterilizer to sterilize the endodontic instruments and $68 \%$ reported about surgical instruments to sterilize by autoclave just after cleaning with detergent wash without using the disinfectant solutions. This study also found that $77.3 \%$ disposed the sharp instruments in plastic container, $20.9 \%$ maintained color code during disposal of medical wastes and $58.2 \%$ respondents used to dispose medical wastes with general wastes. The study revealed that $69.1 \%$ cleaned the non patient area by mop and detergent only. According to the agreements of the respondent's $71 \%$ reported that very few of the patients complained about secondary infection, $81 \%$ gave no history of cross infection after receiving operative procedure. 50.9\% respondents mentioned about participation in training session on infection control procedure at least once in their lifetime. Policy on immunization should be developed for Dental health workers and further studies involving larger sample size is recommended.
\end{abstract}

Key words: Infection control, sterilization, disposable, dental clinics.

\section{Introduction}

Infection is one of the most crucial problems in health care service worldwide.

1. Dr. Ishraque Ahmed BDS, MPH, Consultant, Dept. of Dentistry, Brighton Hospital Pvt. Ltd. Dhaka, Bangladesh.

2. Jony Barua BSN, MPH, Lecturer, Dept. of Nursing, B.Sc. Nursing Unit, International Medical College, Gazipur, Bangladesh.

3. Dr. Khondker Saif Imtiaz MBBS, MPH, DPS, Assistant Professor, Dept. of Community Medicine, International Medical College, Gazipur, Bangladesh.

4. Dr. Sumaiya Zabin Eusufzai BDS, MPH, Senior Lecturer, Dept. of Public Health, Northern University, Dhaka, Bangladesh.

5. Dr. Md. Tomal Mustafa BDS, MDS, TCC, Assistant Professor, Dept. of Oral Anatomy \& Physiology, Sphena Womens' Dental College, Dhaka, Bangladesh.

6. Dr. Muhammad Mubashirul Haque BDS, Medical Officer, Dept. of Dentistry, BIRDEM, Dhaka, Bangladesh.

7. Dr. Nafij Bin Jamayet BDS, M.Sc.Dent, Maxillofacial Prosthodontist \& Senior Lecturer, Maxillofacial Prosthetic Service, Prosthodontic Unit, School of Dental Science, Universiti Sains Malaysia, Malaysia.

Address of Correspondence:

Dr Nafij Bin Jamayet BDS, M.Sc.Dent, Maxillofacial Prosthodontist \& Senior Lecturer, Maxillofacial Prosthetic Service, Prosthodontic Unit, School of Dental Science, Universiti Sains Malaysia, Kubang Kerien, Kotabharu, Malaysia-161500, E-mail- dr.nafij@gmail.com
It constitutes one of the most important causes of morbidity and mortality associated clinical, diagnostic and therapeutic procedures ${ }^{1,2}$ health care workers are at a high risk of needle stick injuries and blood borne pathogens as they perform their clinical activities in hospitals ${ }^{3}$. The Dental clinic is an environment where disease transmission occurs easily ${ }^{4}$. There is growing concern about the issue of cross-infection in Dental clinics and laboratories, especially after several studies found that transmission of infection to dental laboratory technicians is mainly by contaminated impressions or by improper handling of clinical items after arrival at the Dental laboratory ${ }^{5}$. Potential pathogenic microbiologic cross-contamination from various sources by the way of dental laboratory has been documented. In prosthodontic laboratories, lathes and pumice used for polishing and finishing of prostheses have been described as the greatest sources of contamination ${ }^{6}$. Infection control forms an important part of practice for all health care professions and remains one of the most cost-beneficial medical interventions available. In Dentistry, both patients and health care workers may be exposed to a number of blood borne and upper respiratory tract pathogens through exposure to blood and saliva ${ }^{7}$. 
Most studies of Dentists' infection control practices have investigated compliance with specific procedures, such as the use of gloves and masks, eye protection, hepatitis B virus (HBV) vaccination and heat sterilization of dental hand pieces ${ }^{8}$. Exposure to blood through percutaneous injury or by contact to mucous membranes of the eyes, nose or mouth, or by contact with non-intact skin is the primary method in this practice $^{9}$.

\section{Methods and Materials}

This cross-sectional study was conducted in Dhaka city among 110 selected Private Dental practitioners during January to April 2013. Data were collected using a interviewer administered semi-structured questionnaire.

\section{Results}

Table-1 Distribution of the respondents by age $(\mathrm{n}=110)$

\begin{tabular}{|l|c|c|}
\hline Age Group & Frequency & Percentage \\
\hline$<30$ Years & 24 & 21.8 \\
\hline $30-40$ Years & 40 & 36.4 \\
\hline $40-50$ Years & 27 & 24.5 \\
\hline$>50$ Years & 19 & 17.3 \\
\hline Total & 110 & 100.0 \\
\hline
\end{tabular}

Table-1 represents the distribution of the respondents by age. Out of 110 Dental Surgeons $24(21.8 \%)$ were in $<30$ years, $40(36.4 \%)$ were in 30-40 years, $27(24.5 \%)$ were in $40-50$ years and $19(17.3 \%)$ were in age $>50$ years.

Table-2 Distribution of the respondents by duration of clinical practice $(n=110)$

\begin{tabular}{|c|c|c|}
\hline Length of Practice & Frequency & Percentage \\
\hline < 5 Years & 10 & 9.1 \\
\hline 5 -10 Years & 59 & 53.6 \\
\hline 10 - 15 Years & 20 & 18.2 \\
\hline 15 - 20 Years & 12 & 10.9 \\
\hline$>20$ Years & 9 & 8.2 \\
\hline
\end{tabular}

Table- 2 represents distribution of the respondents by length of clinical practice. Out of 110 Dental Surgeons $10(9.1 \%)$ practiced for $<5$ years, $59(53.6 \%)$ for $5-10$ years, $20(18.2 \%)$ for $10-15$ years, $12(10.9 \%)$ for $15-20$ years and $9(8.2 \%)$ for $>20$ years.
Table-3 Distribution of the respondents by treating the number of daily patients $(n=110)$

\begin{tabular}{|c|c|c|}
\hline No. of daily patients & Frequency & Percentage \\
\hline$<5$ & 8 & 7.3 \\
\hline $5-10$ & 33 & 30.0 \\
\hline $10-15$ & 24 & 21.8 \\
\hline $15-20$ & 23 & 20.9 \\
\hline$>20$ & 22 & 20.0 \\
\hline
\end{tabular}

Table- 3 represents respondents by treating the number of daily patients. Out of 110 respondents $8(7.3 \%)$ respondents treated $<5$ patients, $33(30 \%)$ treated 5-10 patients, $24(21.8 \%)$ treated $10-15$ patients, 23 (20.9\%) treated 15- 20 patients and $22(20 \%)$ respondents treated $>20$ patients.

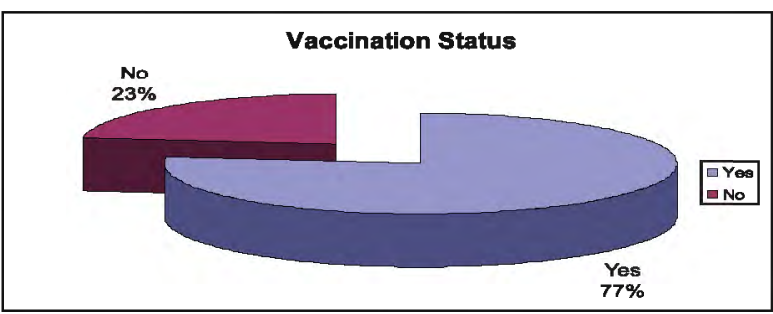

Figure-1 Distribution of the respondents (Dental Surgeons) by having vaccination against Tetanus $\&$ Hepatitis $(\mathbf{n}=110)$

Figure-1 represents distribution of the respondents by having vaccination against tetanus $\&$ hepatitis. Among the respondents $85(77 \%)$ were completely vaccinated against tetanus \& hepatitis and the other $25(22 \%)$ were not vaccinated.

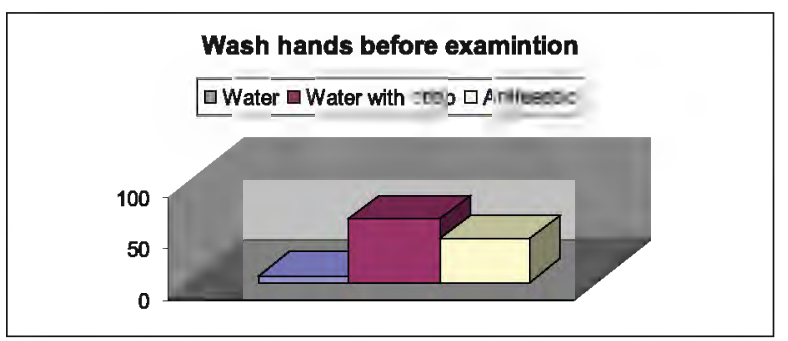

Figure-2 Distribution of the respondents by method of hand washing before patient's examination $(\mathbf{n}=110)$

Figure-2 represents distribution of the respondents by method of hand washing before patient's examination. Table shows that $7(6 \%)$ respondents used water for hand washing, $61(56 \%)$ used water with soap and 42 (38\%) used antiseptic for hand washing. 


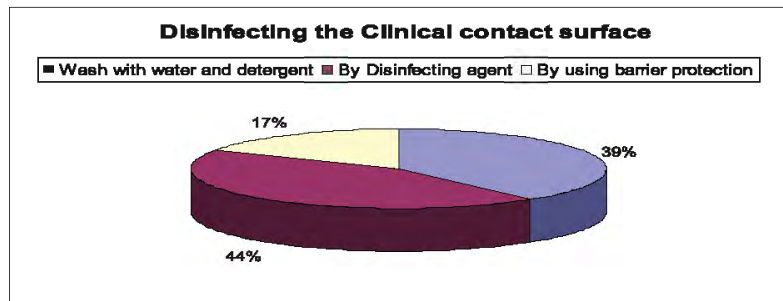

Figure-3 Distribution of the respondents by method of disinfecting the clinical contact surfaces in the Dental operatory $(\mathrm{n}=110)$

Figure-3 Distribution of the respondents on method of disinfecting the clinical contact surfaces in the Dental operatory $(n=110)$. Figure shows that $43(39 \%)$ washed the clinical contact surface by water and detergent, 48 (44\%) by disinfectant agent and rest of $19(17 \%)$ used barrier protection.

Method of cleaning the operatory surface after treatment $\square$ Water $\square$ Water and detergent $\square$ Water and antiseptic $\square$ Disinfectent agent

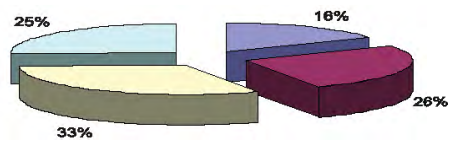

Figure-4 Distribution of the respondents by method of cleaning the operatory surfaces after patient's treatment $(\mathrm{n}=110)$

Figure-4 represents distribution of the respondents by method of cleaning the operatory surfaces after patient's treatment. Figure shows that $18(16 \%)$ were cleaning the operatory surface by water, $29(26 \%)$ by water and detergent, $35(33 \%)$ by water and antiseptic and $28(25 \%)$ cleaned by disinfectant agent.

Table-4 Distribution of the respondents by the use of disposable instruments \& accessories in the clinic $(n=110)$

\begin{tabular}{|l|c|c|}
\hline Disposable Instrument & Frequency & Percentage \\
\hline Syringe & 72 & 65.5 \\
\hline Needle & 110 & 100.0 \\
\hline Cartridge & 40 & 36.4 \\
\hline Suction tips & 101 & 91.8 \\
\hline Surgical blades & 88 & 80.0 \\
\hline Reamer/file/broach/bar & 20 & 18.2 \\
\hline Plastic Glass & 93 & 84.5 \\
\hline
\end{tabular}

*Multiple responses

Table-4 represents distribution of the respondents by the use of disposable instruments \& accessories in the clinic. Table shows that $72(65.5 \%)$ respondents used disposable syringe, $110(100.0 \%)$ used disposable needle, $40(36.4 \%)$ used disposable cartridge, 101 (91.8\%) used disposable suction tips, $20(18.2 \%)$ used disposable reamer/file/broach/bar and 93 (84.5\%) used disposable plastic glass.

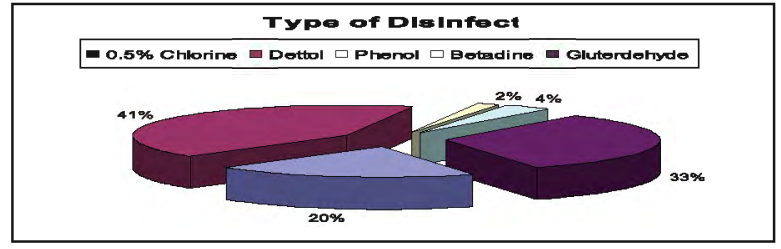

Figure 5 Distribution of the respondents by the type of disinfectants used $(n=110)$

Figure-5 represents distribution of the respondents by the type of disinfectants used in the clinic. Figure shows that $22(20 \%)$ respondents used $0.5 \%$ chlorine, $46(41 \%)$ dettol, 2 (2\%) phenol, 4 (4\%) betadine and rest $36(33 \%)$ used gluteraldehyde.

Table 5 Distribution of the respondents by the type of sterilization procedure $(n=110)$

\begin{tabular}{|l|c|c|}
\hline Sterilization procedure & Frequency & Percentage \\
\hline Autoclave & 81 & 73.6 \\
\hline Hot air oven & 16 & 14.5 \\
\hline Boiling device & 55 & 50.0 \\
\hline Chemical & 74 & 67.3 \\
\hline
\end{tabular}

"Multiple responses

Table- 5 represents distribution of the respondents by the use of sterilization procedure in their clinic. Table shows that $81(73.6 \%)$ respondents were sterilized the instruments by autoclave, $16(14.5 \%)$ by hot air oven, $55(50.0 \%)$ by boiling device and $74(67.3 \%)$ by chemical method.

Table-6 Distribution of the respondents by methods of disinfection of endodontic instruments $(n=110)$

\begin{tabular}{|l|c|c|}
\hline \multicolumn{1}{|c|}{ Disinfect the endodontic instrument } & Frequency & Percentage \\
\hline Detergent wash & 82 & 74.5 \\
\hline Autoclave & 24 & 21.8 \\
\hline Hot air oven & 7 & 6.4 \\
\hline Ultraviolet ray & 10 & 9.1 \\
\hline Boiling & 25 & 22.7 \\
\hline Glass bid sterilizer & 75 & 68.2 \\
\hline
\end{tabular}

* Multiple responses

Table-6 Distribution of the respondents by methods of disinfection of endodontic instruments. Table shows that $82(74.5 \%)$ respondents were disinfect the endodontic instruments by detergent wash, $24(21.8 \%)$ by autoclave, $7(6.4 \%)$ by hot air oven, $10(9.1 \%)$ by ultraviolet ray, $25(22.7 \%)$ by boiling and $75(68.2 \%)$ by glass bid sterilizer.

Table-7 Distribution of the respondents by methods of disinfection of prosthodontic instruments $(n=110)$

\begin{tabular}{|l|c|c|}
\hline Disinfect the prosthodontic instrument & Frequency & Percentage \\
\hline Detergent wash & 81 & 73.6 \\
\hline Autoclave & 14 & 12.7 \\
\hline Hot air oven & 2 & 1.9 \\
\hline Ultraviolet ray & 1 & 0.9 \\
\hline Boiling & 12 & 10.9 \\
\hline
\end{tabular}


Table-7 Distribution of the respondents on methods of disinfection of prosthodontic instruments. Table shows that $81(73.6 \%)$ were disinfected the prosthodontic instrument by detergent wash, $14(12.7 \%)$ by autoclave, 2 $(1.8 \%)$ by hot air oven, $1(0.9 \%)$ by ultraviolet ray and 12 (10.9\%) were disinfected by boiling method.

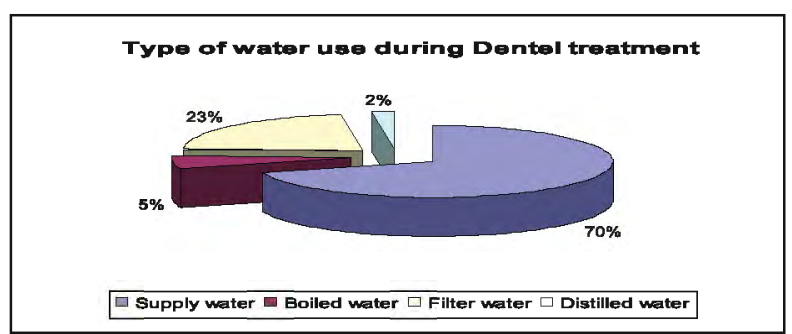

Figure-6 Distribution of the respondents by types of water used during Dental treatment $(n=110)$

Figure- 6 represents distribution of the respondents by types of water used during dental treatment. Above the figure shows that $77(70.0 \%)$ used supply water, $6(5 \%)$, boiled water, $25(23 \%)$ filter water, and only $2(2 \%)$ respondent used distilled water during treatment procedure.

Table-8 Distribution of the respondents by the way of disposal of sharp instruments $(n=110)$

\begin{tabular}{|l|c|c|}
\hline Dispose of sharp waste & Frequency & Percentage \\
\hline Glass container & 8 & 7.3 \\
\hline Metal container & 2 & 1.8 \\
\hline Plastic container & 85 & 77.3 \\
\hline with other wastes together in any container & 15 & 13.6 \\
\hline
\end{tabular}

Table- 8 represents distribution of the respondents by the way of disposal of sharp instruments. Out of 110 respondents, $8(7.3 \%)$ disposed the sharp instrument in glass container, $2(1.8 \%)$ in metal container, $85(77.3 \%)$ in plastic container and $15(13.6 \%)$ disposed the sharp instruments with other wastes together in any container.

Table-9 Distribution of respondents by the methods of cleaning the non patient area $(n=110)$

\begin{tabular}{|l|c|c|}
\hline Clinic clean the non patient area & Frequency & Percentage \\
\hline Mop and detergent only & 76 & 69.1 \\
\hline Mop with detergent when visibly solid & 14 & 12.7 \\
\hline Mop with disinfectant & 20 & 18.2 \\
\hline
\end{tabular}

Table-9 represents distribution of the respondents by the methods of cleaning the non patient area. Out of 11o respondents $76(69.1 \%)$ used mope and detergent only, 14 $(12.7 \%)$ used mop with detergent when visibly solid and $20(18.2 \%)$ used mop with disinfectant solution.

\section{Discussion}

This cross-sectional study was carried out to assess the infection control measures among 110 selected private dental practitioners at Dhaka City of Bangladesh. Among the respondents one-fifth were in age group of $<30$ years, one-third were in age group of 30-40 years, one-fourth were in age group of 40-50 years and around twenty percent were in age group of $>50$ years (mean \pm SD $41.25 \pm 11.953$ years). Among all near about seventy percent were male. By level of education one fourth had diploma level education; sixty percent had completed graduation level. The current study revealed that among the total respondents near about ten percent were involved in this profession for less than 5 years, above half of them for 5-10 years, around one fifth for 10-15 years, ten percent for 15-20 years and less than ten percent for above 20 years (mean $2.55 \pm 1.072$ years). Availability of patients to most of the doctors was on average 5-10 in number per day. According to the results of present study above seventy percent of Dental Surgeons were vaccinated against tetanus and hepatitis. A survey of U.S. Dental laboratories reported that $56.4 \%$ of Dental assistants were vaccinated against hepatitis $\mathrm{B}^{6}{ }^{6}$ One more study carried out by Maupome et al in Mexico City reported that $67.1 \%$ of dental personnel were immunized against hepatitis. Six percent of the respondents used to wash their hands before examining the patients by water, above half of them washed their hands by water and soap together and one-third used antiseptic during hand washing. The most important techniques of "universal precaution" are barrier techniques which include wearing gloves, protective clothing, masks and protective eye wear. Disposable gloves must be worn even when examining the patients. The present study shows that the practice of wearing disposable gloves was above $60 \%$, disposable masks $70 \%$, and one-fourth wearing disposable clothes. The study exposes that above $60 \%$ of respondents' the assistants used PPE and around $67 \%$ respondents' assistants used gloves during cleaning and disinfecting procedures. The study carried out by Razak et al (1995) in Malaysia concluded that $54.0 \%$ of the respondents routinely wear gloves and about $83.0 \%$ of dentists wear mask. South African Dentists used gloves by $87.0 \%$. Aziawa et al (1996) stated that gloves and other protective garments were generally worn. ${ }^{11,12,13,14}$ Among the respondents dealing with clinical contact surface in the Dental operatory, above forty percent used to wash with water and detergent, less than $45 \%$ used disinfectant agent and below $20 \%$ used barrier protection. 
In case of the use of variety of disinfectants in the clinics it is observed that one-fifth used $0.5 \%$ chlorine, $41 \%$ used dettol, $2 \%$ used phenol, and $4 \%$ used betadine and above one-third used gluteraldehyde. To perform the sterilization of instruments in the dental clinic above one-third used autoclave. Dealing with the sterilization of endodontic instruments this study shows that above $35 \%$ respondents used detergent wash, above $10 \%$ used autoclave and above $30 \%$ used to use glass bid sterilizer. On the other hand for prosthodontic instruments more than $70 \%$ participants agreed to use detergent wash, more than $10 \%$ used autoclave and also more than $10 \%$ used boiling device. Surgical instruments intended for sterilization and disinfections must be done carefully. Among the respondents below $70 \%$ gave the history of cleaning their instruments firstly by water and detergent and secondly using the autoclave. School of Dentistry, Virginia, USA, expressed their faculty practice as instrument preparation includes ultrasonic cleaning in a bacterium cleaning solution. This study revealed that water and soap was the most common antiseptic solution for cleaning the instruments. No other significant study was observed between degree and cleaning practice of instruments. ${ }^{11-15}$ About the types of water used in the Dental clinics during treatment it is observed here that $70 \%$ participants used supply water. Among the dental professionals as a matter of disposal of sharp instruments we get the data of $8 \%$ using glass container, $2 \%$ using metal container, above $70 \%$ using plastic container and below $15 \%$ disposing the sharp instruments with other wastes together in any container. The study revealed that non patient area in the clinics were cleaned with mop and detergent only by around $70 \%$ and around $20 \%$ used mop with disinfectant.

\section{Conclusion and Recommendations}

Infection control is a burning topic in health care, especially in Dentistry. Dental staff should have most up to date knowledge about the procedures required to prevent the transmission of infection. Among the respondents majority were male and graduate, and half of respondents were practicing for 5-10 years. Among the respondents eighty percent were completely vaccinated against tetanus and hepatitis. The current study revealed that among the respondents above seventy percent used disposable gloves and protective eye wear and seventy percent used disposable masks during practice. On the basis of findings of the study following recommendations may be made, the Ministry of Health has to provide formal intensive training courses on infection control for the Dental professionals of all categories
Before issuing license to the Dental clinics special attention needs to be given on the infection control status of the clinic, policies and programs should be developed and implemented for Dental health workers in respect of training, education and self immunization, further studies on the topic involving larger sample size are needed.

\section{References}

1. Lacerda RA. Infeccao hospitals e sua relacao com a evolucao das practices de assistencia a sude. In: Lacerda RA, ed. Controle de infeccao em centro cirurgico. Sao Paulo: Atheneu, 2003: 9-23.

2. Laclerda RA, Egry EY. As infeccoes hospitalares e a sua relacao com o desenvol vimento da assistencia hospitalar: reflexoses para analise practicas atuais de controle. Rev Latinoam Enfermagem 1997; 5:13-23.

3. Beltrami EM, Williams IT, Shapiro $\mathrm{CN}$, et al. Risk and management of blood borne infections in health care workers. Clin Microbiol Rev 2000; 13(3):385-407.

4. Taiwo JO, Aderinokun GA.Assessing cross infection prevention measures at the Dental Clinic, University College Hospital, Ibadan. Afr J Med Med Sci. 2002 Sep; 31(3):213-7.

5. Verran J, Kossar S, McCord JF. Microbiological study of selected risk areas in dental technology laboratories. J Dent 1996; 24:77-80.

6. Kugel G, Perry RD, Ferrar M, Lalicata P. Disinfection and communication practices: a survey of U.S. dental laboratories. J Am Dent Assoc 2000; 131(6):786-92.

7. Wenzel RP. The Lowbury lecture. The economics of nosocomial infections. J Hosp Infect 1995; 31:79-87.

8. McCarthy GM, Koval JJ, MacDonald JK. Factors associated with refusal to treat patients with HIV-infected patients: the results of a national survey of dentists in Canada. Am J Public Health 1999; 89:541-5.

9. Petty T L. Infection Prevention and Control in the Dental Office: An opportunity to improve safety and compliance. Available on http://www.sdaa.sk.ca/ Workplace\%20Issues/ Health\&Safety.pdf/CDA-InfectionControlManual2006.pdf

10. Rahaman MM. Use of needles and syringes by the rural practitioners and their method of sterilization (dissertation) NIPOSM, Dhaka University, 1992.

11. American dental association. Infection control recommendations for the dental office and dental laboratory, 2002. http//www.ada.org/prof/pubs/ nigf.html

12. Razak IA and Linda OP. Cross infection control in Malaysian dental practice. Singapore-dent-j 1995 Jul; 20 (1): 11-5.

13. Aziawa F, Yone MM, Aziawa Y, Hanada N, Akada H. A survey on infection control practices, knowledge and attitudes towards AIDS/HIV among dental practitioners. Nippon-Koshu- Eisei-Zasshi 1996 May; 43 (5): 364-73.

14. Naidoo S. Dentist and cross infection. J-Dent-Assoc-S-Afr 1997 Mar; 52 (3):165-7.

15. Anonymous. Steam remains preferred method of sterilization. 2001. Http//dentistry.vh.org/html 